\title{
Espaço, atendimento de saúde e sexualidades segundo a vivência Travesti em Ponta Grossa - Paraná
}

\section{Space, health care and sexualities according to the experience of Travestis in the city of Ponta Grossa city, Paraná}

\author{
Espacio, atención a la salud y sexualidades según la vivencia \\ Travestí en Ponta Grossa - Paraná
}

\author{
Marcia Tobias Carneiro \\ marcy_tc@hotmail.com \\ Universidade Estadual de Ponta Grossa \\ Marcio Jose Ornat \\ geogenero@gmail.com \\ Universidade Estadual de Ponta Grossa
}

\begin{abstract}
Resumo: Esta discussão problematiza a relação entre espacialidades, atendimento de saúde e sexualidades, segundo a vivência travesti na cidade de Ponta Grossa, PR. Considerando que o espaço é constituído por inter-relações, esfera da multiplicidade e sempre em construção, evidenciamos que as vivências espaciais também são realizadas por pessoas que extrapolam a linearidade entre sexo, gênero e desejo. Contudo, a análise de entrevistas realizadas com oito travestis apontam que as espacialidades da saúde colocam-se enquanto interditadas à vivência deste grupo. A Ciência, além de ser uma atividade histórica e sociológica, é também uma atividade política. Portanto, a problematização deste fenômeno ancora-se na demanda da efetivação das políticas públicas, a partir de práticas de atendimento orientadas pela equidade e pelo respeito às diferenças.
\end{abstract}

Palavras-Chave: Travesti. Atendimento de Saúde. Espacialidade da Saúde.

\begin{abstract}
This article problematizes the relationship between spatiality, sexualities, and health care from the point of view of travestis living in the city of Ponta Grossa, Paraná. Spatialities are constituted for interrelations; they are a sphere of multiplicity and they are always under construction. This configuration shows that people are capable of spatial experiences that exceed the linearity between sex, gender and desire. However, the analysis of the interviews with eight travestis demonstrates that the spatiality of health is interdicted for the experience of this group. Scientific production is more than a historical and sociological activity; it is also a political activity. Therefore, the questioning of this phenomenon is anchored in the demand for effective public policies and for care practices guided by fairness and a respect for differences.
\end{abstract}

Keywords: Travesti. Health care. Spatiality of health.

Resumen: Esta discusión problematiza la relación entre espacialidades, atenciones a la salud y sexualidades, según la vivencia travestí en la ciudad de Ponta Grossa - Paraná. Dado que el espacio es constituido por inter-relaciones, esfera de la multiplicidad y 
siempre en construcción, evidenciamos que las vivencias espaciales también son realizadas por personas que sobrepasan la linealidad entre los sexos, género y deseo. Sin embargo, el análisis de entrevistas realizadas con ocho travestis apuntan que las espacialidades de la salud se ponen como interditadas a la vivencia de este grupo. La Ciéncia, además de ser una actividad histórica y sociológica, también es una actividad política. Así, la problematización de este fenómeno se basa en la demanda de la efectivación de las políticas públicas, por medio de práticas a la atención orientadas por la equidad y por lo respecto a las diferencias.

Palavras-Clave: Travestí. Atención a la Salud. Espacialidad de la Salud.

\section{INTRODUÇÃO}

A presente reflexão tem por objetivo compreender de que forma a espacialidade da saúde é vivenciada pelo grupo de travestis na cidade de Ponta Grossa, PR. A ciência geográfica brasileira apenas recentemente tem aberto espaço para as temáticas relacionadas com as interfaces entre espacialidades e sexualidades e, mais especificamente, problematizando a vivência de grupos que não correspondem à linearidade entre sexo, gênero e desejo.

Apesar de ser um campo de discussão estabelecido há mais de trinta anos na produção anglófona (OBERHAUSER, et al, 2003; MCDOWELL, 2003), esta possibilidade geográfica não tem recebido a devida atenção dos geógrafos brasileiros, como apontado por Silva (2009a). A comparação do volume da produção brasileira com o total da produção geográfica anglófona - publicada ${ }^{1}$ em periódicos geográficos e não geográficos - evidencia a ignorância relacionada à riqueza desta possibilidade.

A discussão geográfica relacionada à vivência travesti já vem sendo discutida através da produção brasileira, como, por exemplo, nos trabalhos de Silva (2009b, 2013) e Ornat $(2008 ; 2009,2011)$. Estes pesquisadores problematizaram as experiências vivenciadas pelas travestis em suas trajetórias de vida, evidenciando que estas pessoas enfrentam preconceitos e constrangimentos na maioria das espacialidades, estando dentre estas as espacialidades da saúde.

Muitas questões ainda são pouco exploradas pela Geografia, produzindo não ditos geográficos, como os relacionados às exclusões sociais e às interdições espaciais vivenciadas cotidianamente por pessoas com práticas não correspondentes à heteronormatividade vigente. Embora se justifique a existência da relação entre Geografia e Sexualidades, essas discussões ainda são ditas como não geográficas, ocupando a margem das produções científicas brasileiras, tanto na Geografia quanto dentro das Ciências Sociais.

Em termos de produtividade científica, a temática Saúde vem crescendo com o passar dos anos e se fortalecendo como um novo subcampo da ciência geográfica brasileira, sob o nome de Geografia da Saúde. No Brasil, as discussões sobre saúde

1 Como exemplo, os periódicos Gender, Place and Culture, Area, Progress in Human Geography, Environment and Planning D: Society and Space, Sexualitities. 
na perspectiva geográfica estabelecem-se desde o final do século $X X$, paralelamente à implantação do Sistema Único de Saúde (SUS), interessando-se pelas problematizações acerca da distribuição espacial, do aperfeiçoamento de sistemas de saúde, procurando identificar locais e situações de riscos, dando subsídios ao planejamento territorial de ações e atividades de prevenção, e proporcionando assistência médica aos usuários (PEREHOUSKEI; BENADUCE, 2007). Contudo, a mesma ainda não produziu visibilidade para as questões referentes ao acesso e ao atendimento das pessoas trans, mais especificamente às travestis, que pela sua corporeidade e transgressão da norma vigente, demandam discussões espaciais de suas vivências sociais, pois, como afirmado por Cosgrove (1998), a Geografia está em toda parte.

Assim, para o desenvolvimento desta discussão, problematizamos os resultados obtidos da realização de entrevistas semi-estruturadas com oito pessoas que se autodenominam como travestis e que, de forma contínua ou descontínua, estiveram envolvidas com a atividade da prostituição. O total de 3 horas e 30 minutos de diálogo produzido pelo processo de pesquisa foi analisado segundo a proposta de Bardin (1977), a partir da análise de conteúdo dos discursos, conforme o estabelecimento de redes semânticas que tratavam das espacialidades ou de fatos que ocorreram através das espacialidades, que se articulam e que foram se associando durante as suas trajetórias de vida.

Este processo metodológico refere-se ao desmembramento do texto - no caso, da fala resultante do processo de entrevista - em unidades denominadas de evocações, para em seguida processar o reagrupamento de acordo com estas mesmas categorias, ou, como a partir de nosso olhar, segundo espacialidades discursivas. Em um momento seguinte, estes mesmos trechos de entrevistas desmembrados são organizados segundo 'categorias discursivas' de recordações de fatos que se referiam às espacialidades ou tratavam das espacialidades.

O resultado das 201 evocações que nasceram deste processo de análise evidencia uma vivência espacial estruturada por processos de exclusão social e interdição espacial. Como tratado por Morin (1996), a Ciência não é apenas científica, mas, sim, histórica e sociológica. Todavia, esta discussão coloca-se além de um projeto científico, apresentandose também como um projeto político de emancipação social.

\section{ESPACIALIDADES E PRODUÇÃO DO ESPAÇO INTERDITO NA VIVÊNCIA TRAVESTI}

O espaço geográfico foi pensado e problematizado por autores geógrafos e não geógrafos, como aponta Corrêa (1995), e que subsidiaram a produção de inteligibilidade aos fenômenos espaciais. Uma destas propostas refere-se à proposição de Lefebvre (1991²), em sua obra La Production de L'Espace, destacando a produção do espaço capitalista contemporâneo, levando-se em consideração as relações práticas do cotidiano.

2 Primeira publicação em francês no ano de 1974. 
Segundo o autor, o Estado planeja e organiza racionalmente o espaço para os interesses do capital, através do conhecimento e da tecnologia produzidos com esta função. O espaço é, portanto, uma ferramenta essencial para os pensamentos e as ações, além de meio de produção e controle, impondo uma ordem temporal e espacial que envolve elementos materiais e imateriais. É nesse aspecto que os sujeitos que se julgam normais, como elemento de superioridade, fazem leituras sobre a imagem e índole das travestis, devido a sua não correspondência entre corpo e gênero. Estas, por sua vez, tentam reconstruir-se buscando seu lugar a partir das relações com o espaço.

Em se tratando de elementos materiais, Souza (1997) discute a importância da materialidade do espaço que é produzido pelas relações sociais, em que as estruturas e formas espaciais podem ou não facilitar a articulação desses elementos e dos indivíduos. Para o autor, a configuração da materialidade do espaço deve ser pensada como organizada visando o controle e a segurança. Assim, a cultura, os símbolos e signos representantes dessa materialidade devem ser levados em consideração, pois mantêm vínculos com a formação e reprodução de identidades.

De modo geral, Souza (1997) propõe que a organização espacial está atrelada à produção e às tecnologias, às relações de poder e às representações sociais de uma sociedade, estando adaptada a cada transformação social, sendo reflexo e condição dela. Nessa ideia de organização espacial e adaptação social, as espacialidades criam constrangimentos aos sujeitos, conforme sua sexualidade. Os grupos homossexuais, e em específico as travestis, tencionam sua posição de margem, buscando visibilidade e representatividade através do espaço.

O ato de criação e organização do espaço geográfico é um processo prático e simbólico. Assim a prática social que produz o espaço é antes vivida do que conceituada. O passado deixa suas marcas pelo espaço, mas o espaço é presente com sua totalidade atual, considerando nessa totalidade todos os grupos sociais, os que atendem à norma binária vigente em termos de padrão de sexualidade, e os que transgridem essa heterossexualidade. Lefebvre (1991) chama a atenção para três fatores importantes: a prática social que é o cotidiano; as representações do espaço, que envolvem o trabalho dos cientistas, planejadores, urbanistas, tecnocratas; e os sistemas de engenharia e os espaços representacionais, que se constituem dos símbolos e das imagens. Esta tríade compõe uma só totalidade inseparável.

Esta tríade teórica, onde o espaço é socialmente produzido, ou seja, vivido, percebido e concebido, possibilitou e influenciou os estudos de Milton Santos. Para Santos (1978), corroborando com a ideia de Lefebvre, o espaço é considerado como um conjunto de formas que representam as relações sociais do passado e presente, que se manifestam por meio de processos e funções, onde a aceleração e a evolução espacial são desiguais em todos os lugares. Essa desigualdade é aparente na espacialidade da saúde, como evidenciado no campo, pois ao mesmo tempo em que em alguns locais o atendimento de saúde às travestis vai ao encontro das políticas públicas direcionadas a este grupo, em outros, a interdição ao acesso à saúde pública é substantiva. 
Para Santos (1978), o espaço social é uma realidade objetiva, sendo que a interpretação da realidade espacial não se baseia nas percepções, mas se dá através das produções socioespaciais. $\mathrm{O}$ autor, a partir destas proposições, concebe o espaço como uma estrutura social ou nível da sociedade. Por isso se torna um reflexo da sociedade global, considerando-o também como um fator social que se impõe a toda sociedade. Ele pode ser condicionante e até, de certa forma, determinante para a evolução de outras estruturas sociais, pois:

O espaço, como as outras instâncias sociais, tende a reproduzir-se, uma reprodução ampliada, que acentua os seus traços dominantes. A estrutura espacial, isto é, o espaço organizado pelo homem é como as demais estruturas sociais, uma estrutura subordinada-subordinante. E como as outras instâncias, o espaço, embora submetido à lei da totalidade, dispõe de uma certa autonomia que se manifesta por meio de leis próprias, específicas de sua própria evolução. (SANTOS, 1978, p. 145).

O espaço não é uma superfície neutra, mas um condicionante-condicionado, tais como as demais estruturas sociais, dotada de um dinamismo próprio e com certa autonomia, em que há o diálogo entre forma, conteúdo e sujeitos. A visão de Santos (1978) sobre o espaço dá embasamento a nossa discussão, mas não atende totalmente nossa proposta. Concordamos que as relações sociais através do espaço são reflexo dos elementos que o compõem. No entanto, as leis que deveriam dinamizar em sua totalidade não se aplicam a todos os indivíduos. A partir disso ocorrem os constrangimentos espaciais que as travestis vivenciam ${ }^{3}$.

Diante da dinamicidade do espaço, trazemos à discussão a abordagem alternativa proposta por Massey $\left(2008^{4}\right)$. Segundo a autora, o espaço é problematizado a partir de três considerações: $1^{\circ}$ ) o espaço como produto de inter-relações, constituído por meio de interações do global ao local; $2^{\circ}$ ) o espaço como esfera da existência da multiplicidade, da pluralidade contemporânea, onde a heterogeneidade coexiste, sem multiplicidade não há espaço; $3^{\circ}$ ) o espaço está sempre em construção, produto de relações inseridas em práticas materiais que devem ser efetivadas.

Entender o espaço como produto de inter-relações reivindica uma política de identidades, ou seja, de respeito e igualdade às múltiplas identidades existentes, e que, a partir das relações com as espacialidades, estas são constituídas. É destas relações que são vivenciadas pelos grupos sociais, em específico ao nosso grupo focal de travestis, que se estabelecem os elementos de inclusão e exclusão em espaços onde a insistência à prevalência da ordem binária é frequente.

Imaginando o espaço como esfera da possibilidade de multiplicidade, no que diz respeito à heterogeneidade, através do reconhecimento da espacialidade, Massey (2008) chama a atenção para uma visão do espaço diferente das construídas no Ocidente durante a modernidade, visto como morto, fixo e atemporal, ou ainda, contado e experienciado

\footnotetext{
3 Nosso objetivo não é avaliar até que ponto estes constrangimentos ocorrem, mas evidenciar sua existência.

4 Título original For Space, de 2005, tradução em português de Hilda Pareto Maciel e Rogério Haesbaert. Publicado no Brasil em 2008.
} 
apenas pelo masculino, branco e heterossexual. A coexistência dessa simultaneidade espacial - dando voz aos vários sujeitos em suas trajetórias distintas, sem essas estarem desconectadas - é onde se efetiva a contemporaneidade radical da diversidade e suas relações, pois "o espaço é igualmente vivo e igualmente desafiador, e que longe de ser morto e fixo, a própria enormidade de seus desafios significa que as estratégias para dominá-lo têm sido muitas, variadas e persistentes." (MASSEY, 2008, p. 35).

Conectando a ideia de que o espaço é vivo e dinâmico, Massey (2008) pensa o espaço como em constante processo, aberto e frequente nos discursos políticos, e como elemento caracterizador do futuro nas narrativas da modernidade. Nessa perspectiva, num espaço aberto, as interações podem ser sempre construídas e reconstruídas, ou, como proposto por Lefebvre (1991) e Santos (1978), produzidas e reproduzidas socialmente.

Para Massey (2008), a espacialidade que se mantém em constante movimento é, portanto, uma simultaneidade dinâmica, constantemente alterada pela inter-relacionalidade e permanentemente em construção, a partir de novas relações. Através desse conceito, faz-se valer o reconhecimento das relações nas várias espacialidades, entre elas a espacialidade da saúde.

Corroborando a ideia de Massey (2008), a proposição de Rose (1993) parte da perspectiva do 'Espaço Paradoxal', na qual chama atenção para as configurações de poder que se estabelecem entre centro e margem da configuração espacial. Portanto, em vez de visualizarmos os corpos travestis em processos de inclusão e exclusão, evidenciamos a partir da proposta da autora que há uma simultaneidade entre poder e resistência na composição espacial. Assim, é preciso compreender tanto o que é 'visível' quanto o que é 'invisível' , já que ambos fazem parte da mesma realidade espacial que é simultaneamente contraditória e complementar.

Rose (1993) coloca este sujeito feminino ${ }^{5}$ como desafiador do dualismo homem/mulher, indo além dos discursos dominantes, dando um sentido próprio e articulado frente às espacialidades. Essa proposta de desafio da ordem binária remete também ao grupo das travestis, que, segundo Valentine (1993), buscam legitimar suas ações através do espaço, a fim de apropriar e dominar lugares, desafiando esta ordem dominante, fomentando experiências espaciais que muitas vezes são invisíveis e produzidas na margem.

A ideia de espaço paradoxal de Rose (1993) traduz bem a (in)visibilidade dada aos sujeitos trans, especialmente as travestis, que, segundo a própria autora em Performing Space (1999), articulam fantasias, discursos e corporeidades. Rose (1999) argumenta que as performances corporais são marcadores de inclusão e exclusão, produzindo e reproduzindo espacialidades.

Consideramos que dentre a infinidade de possibilidades, encontra-se a espacialidade da saúde, que muitas vezes é constituída por processos de estigmatização da corporeidade das travestis, interditando seu acesso ao seu atendimento. As travestis são alvo de estigmas, constrangimentos e violências em seus cotidianos, sejam em espaços

5 Salientamos que as travestis compõem este sujeito feminino, não visto de forma singular. Mesmo que sejam homens no sentido fisiológico, as travestis vivem 24 horas por dia como mulheres, transformando seus corpos a partir de suas feminilidades desejadas. 
públicos ou privados, independentes de sua localização na configuração, isto é, centro ou margem.

Para refletirmos sobre a questão dos estigmas enfrentados pelas travestis, utilizamos a problematização de Goffman $\left(2004^{6}\right)$, que pontua:

O termo estigma [faz] referência a um atributo profundamente depreciativo, mas o que é preciso, na realidade, é uma linguagem de relações e não de atributos. Um atributo que estigmatiza alguém pode confirmar a normalidade de outrem, portanto ele não é, em si mesmo, nem horroroso nem desonroso. (GOFFMAN, 2004, p. 6).

Isto evidencia-se nas falas das travestis que cederam suas histórias de vida à construção desta discussão. As ações de estigmatização com seus processos surgem das relações sociais e vivências espaciais, fundamentadas em valores e significações culturais que dão base às condutas e comportamentos dos que compõem o padrão de normalidade.

Goffman (2004) categoriza três tipos de estigmas que se caracterizam por meio dos atributos que os indivíduos carregam. Em primeiro lugar seriam as deformidades físicas do corpo, que são elementos de exclusão para vários sujeitos que a têm; em segundo lugar, as de caráter individual, consideradas como estigmas de fragilidades, tais como distúrbio mental, prisão, vício, alcoolismo, homossexualidade, desemprego, tentativas de suicídio e comportamento político radical; e em terceiro lugar, há os estigmas relacionados à raça, etnia e religião, que perpassam as relações familiares através das gerações.

Estes tipos de estigmas possuem relação com a compreensão dos fenômenos de abjeção, conforme a proposta de Butler (2008), como referentes ao gênero, à sexualidade e à corporeidade, gerando interdições e exclusões em diferentes espacialidades. Nesta lógica, heteronormatividade e espacialidades são coconstitutivas. Contudo, em certa medida, nossa convivência com o grupo de travestis aponta para o fato de que suas vivências, ao mesmo tempo tensionam e subvertem a ideia de que o sexo é o definidor do gênero, e consequentemente do desejo, atribuindo uma manifestação paradoxal à coconstituição de espacialidades e heteronormatividade.

Segundo Butler (2003), a performatividade - ou, nos termos da autora, o gênero performativo - relaciona-se à reiteração de um conjunto de normas que são anteriores aos sujeitos. Devido ao fato da repetição estilizada de atos, segundo um processo de substancialização, ou seja, tornar-se substância, a linearidade entre sexo, gênero e desejo recebe o atributo de condição natural do ser. Neste caminho, para a autora, a heteronormatividade seria a forma dita padrão e correta de prática sexual, referente à norma heterossexual.

Contudo, no que diz respeito a sua subversão, ultrapassando as interdições vivenciadas nas espacialidades, Silva (2013) propõe a produção do conceito do 'Espaço Interdito', de acordo com as ideias de Michel Foucault, baseado na ideia de que espacialidades e heteronormatividade são compostas e compõem discursos. Assim, segundo a autora, se o espaço é produzido por relações de poder, pode-se afirmar que o espaço é heteronormativo, pois um dos padrões discursivos estabelecidos de comportamento social refere-se à

6 Obra intitulada Stigma - Notes on the Management of Spoiled Identity, publicada originalmente em 1963, disponibilizada digitalmente e traduzida para o português em 2004. 
linearidade entre sexo, gênero e desejo. Àqueles corpos que não corresponderem a esta linearidade, resta a interdição. Neste caminho, o espaço interdito é:

[...] concebido como o efeito da ordem discursiva espacial em que práticas regulatórias são desempenhadas por aqueles que se julgam dentro da ordem e possuem o poder de exercê-la, bem como o de estabelecer as formas com que determinados sujeitos devem ser excluídos. O espaço interdito é efeito das relações de poder que são onipresentes, e assim, sua constituição é vista como algo natural, sendo incorporado por todos os que fazem parte do campo discursivo. (SILVA, 2013, p. 159).

Como afirmado pela autora e corroborado nas respostas do campo, a interdição se revela quando a ordem é desafiada. Neste sentido, toda ação de transgressão revela quais são os limites de vivência espacial que os grupos possuem. É segundo as interdições das vivências travestis que buscamos compreender esta desigualdade substantiva, que interdita o acesso garantido por lei à Saúde Pública.

\section{ESPACIALIDADES, SEXUALIDADES E ATENDIMENTO DA SAÚDE}

A perspectiva de articulação entre os diversos sujeitos, relacionando-se com a vivência espacial, foi evidenciada, de forma direta ou indireta, nas concepções de Lefebvre (1991), Santos (1978) e Massey (2008), nos trazendo a ideia defendida por Feyerabend (1975), de maneira que a epistemologia é uma forma de desordenar e reordenar, ou seja, 'tudo vale' dentro da Ciência. Uma das concepções utilizadas para fundamentar as pesquisas sobre sexualidades remete-se à proposta de Michel Foucault, em a História das Sexualidade I - a vontade do saber (1988), referente ao dispositivo da sexualidade. Este autor evidencia o quanto as práticas sexuais trazem em seu bojo um exercício do poder, disciplinando os corpos e regulando as populações.

Os estudos realizados por Michel Foucault sobre a História da Sexualidade ${ }^{7}$ produziu ricos elementos norteadores para as pesquisas relacionadas à temática, possibilitando contextualizações em diversos campos da ciência geográfica, articulando proposições que dão conta de produzir inteligibilidade aos sujeitos que não correspondem à ordem heterossexual vigente.

Nesse caminho, buscamos problematizar as experiências vivenciadas pelas travestis em diferentes espacialidades. Com a concepção de que as espacialidades são referenciais de sobrevivência, fontes de poder e, assim, sendo alvo de desejo (SOUZA, 1997), a Geografia vem abordando sob várias vertentes as dinâmicas que ocorrem através do espaço. Um dos subcampos que vem ganhando força nos últimos anos é a Geografia da Saúde.

A Geografia da Saúde é um subcampo relativamente novo, em comparação aos demais caminhos de discussão na ciência geográfica brasileira. As discussões

7 Além da obra 'História da Sexualidade I - a vontade do saber', de 1988, foram publicadas a 'História da Sexualidade II - o uso dos prazeres' (1984), traduzida para o português, e 'Historia de la Sexualidad III - la inquietud de si' (1987), traduzida para o espanhol. 
encontram-se num número pequeno de publicações, como fora evidenciado a partir de um levantamento ${ }^{8}$ sistemático realizado nos dois principais bancos de dados sobre produção científica brasileira já realizada, no Banco de Teses e Dissertações da CAPES $^{9}$, e na Biblioteca Digital Brasileira de Teses e Dissertações do IBICT.

Este levantamento demonstrou um total de $87^{10}$ trabalhos que discutem a saúde sob a perspectiva geográfica. Porém, dentre esses trabalhos não foi encontrado nenhum que problematizasse a relação entre espacialidades da saúde e gênero - sexualidades. Para Guimarães (2001), um dos precursores deste subcampo no Brasil, a partir do XII Encontro Nacional de Geógrafos Brasileiros, em Florianópolis, SC, ocorrido no ano de 2000, quando foram promovidas atividades com enfoque na Saúde Pública, inicia-se uma discussão sob um novo paradigma, demonstrando a preocupação e o envolvimento dos geógrafos em relação às temáticas da saúde, antes não problematizadas. Apesar da busca de um novo paradigma para a questão da Saúde Pública pela Geografia, a mesma ainda não produziu visibilidade para as questões referentes ao acesso e ao atendimento das pessoas trans, para que se efetivem as políticas públicas necessárias à não interdição e exclusão desse grupo.

Em relação às políticas públicas que compõem ações à saúde do grupo das travestis, direta ou indiretamente, partimos da premissa segundo os princípios do SUS, que prima pelo atendimento com equidade para todos, embora se saiba que nem todas as pessoas são iguais, mas que as diferenças sejam respeitadas (MINISTÉRIO DA SAÚDE, 1990). Apesar de se tratar de um princípio norteador nas espacialidades da saúde, para se atender a demanda das necessidades dos grupos homossexuais, que ainda são considerados como vulneráveis, foram elaborados programas com ações e metas que efetivem o atendimento aos sujeitos compositores desses grupos, dentre eles, o grupo das travestis.

Uma das demandas de implantação à saúde dos grupos homossexuais, mas que atende ao grupo dos heterossexuais, aconteceu no ano de 1986, na mesma década que fora diagnosticado o primeiro caso AIDS no Brasil. Para isto foi criado o Departamento de DST, AIDS e Hepatites Virais, ligado à Secretaria da Vigilância em Saúde do Ministério da Saúde, que tem por premissa dois grandes objetivos: $1^{\circ}$ ) reduzir a transmissão do HIV, das doenças sexualmente transmissíveis e das hepatites virais; e $2^{\circ}$ ) melhorar a qualidade de vida das pessoas com essas enfermidades. Lembramos que se estas políticas públicas tratam de grupos sociais vulneráveis, podem as travestis serem nominadas como compositoras deste grupo. A partir disso, grupos de militância LGBT são criados no país a fim de promover a cidadania e luta pelos direitos de gays, lésbicas, bissexuais, travestis e transexuais, afirmando a livre orientação sexual e de identidade de gênero.

8 Pesquisa realizada às 21h20min do dia 20 de abril de 2012, utilizando apenas o campo assunto com a palavra-chave ‘Geografia da Saúde' e selecionando o campo expressão exata, desde o ano de 1987 nos níveis de mestrado e doutorado.

9 Segundo a Portaria $n^{\circ}$ 013, publicada em 15 de fevereiro de 2006, que institui a divulgação digital de Teses e Dissertações produzidas pelos programas de Doutorado e Mestrado reconhecidos - e atualizados anualmente por meio do software COLETA, que é um aplicativo de coleta de dados informatizado, desenvolvido com o objetivo de coletar informações dos cursos de mestrado, doutorado e mestrado profissional integrantes do Sistema Nacional de Pós-Graduação.

10 Apesar de os bancos de dados trazerem mais resultados, após uma análise do resumo foram obtidos 87 trabalhos oriundos de Cursos de Pós-Graduação de Geografia. 
Outro projeto implantado com vistas a atender os grupos citados, é o 'Brasil sem Homofobia - Programa de Combate à Violência e à Discriminação contra GLTB'11 e de Promoção da Cidadania Homossexual, lançado em 2004, iniciativa do governo federal, que visava garantir os direitos humanos de todos os homossexuais, e ainda como um dos objetivos norteadores, a mudança de comportamento dos gestores públicos, com adoção da não violência contra estes grupos estigmatizados pela sociedade. Entretanto, das 53 ações destinadas à promoção do respeito à diversidade sexual, apenas 5\% são sobre o direito à saúde, que visam elaborar estratégias para atenção a esses grupos.

Mais direcionado à questão da saúde foi o projeto criado em 2007, denominado 'Plano de Enfrentamento da Epidemia de AIDS e das DST entre Gays, HSH (Homens que fazem sexo com homens), e Travestis', que traça diretrizes que expressam o compromisso das três esferas de governo - federal, estadual e municipal - juntamente com a sociedade civil, visando a implantação de uma política pública de prevenção e controle da DST/ AIDS, a partir do reconhecimento das vulnerabilidades que estes grupos possuem em relação à saúde. Corroborando com as diretrizes do Programa Brasil sem Homofobia, o plano contou com a ajuda destes grupos vulneráveis e também de profissionais e gestores de saúde, de modo a viabilizar uma melhor abordagem dentro dos espaços onde há diversidade sexual e de identidade de gênero.

Em relação ao grupo específico das travestis, o plano reservou uma Agenda Afirmativa que tinha como proposta cumprir metas no período dos anos de 2007 a 2011, tendo como objetivo geral enfrentar a epidemia do HIV/ AIDS e as DST deste e dos outros grupos citados, por meio da redução das vulnerabilidades, estabelecendo política de prevenção, promoção e atenção integral à saúde.

No compasso do programa Brasil sem Homofobia (2004), no ano de 2010 foi implementado no país a Política Nacional de Saúde Integral de Lésbicas, Gays, Bissexuais, Travestis e Transexuais, de caráter transversal, compondo-se de um conjunto de diretrizes cuja operacionalização requer planos contendo estratégias e metas sanitárias. A política conta com o objetivo geral de promover a saúde integral desses grupos, eliminando a discriminação e o preconceito institucional, contribuindo para a redução das desigualdades e a consolidação do SUS como sistema universal, integral e equitativo, além de mais 26 objetivos específicos, com responsabilidades atribuídas ao Ministério da Saúde, Secretarias Estaduais e Secretarias Municipais de Saúde.

Ainda para que se garanta o respeito à condição do ser travesti nas espacialidades da saúde, existe o respaldo legal pelo direito de utilizar o nome social de preferência, conforme Portaria do Ministério da Saúde n 675, de março de 2006, substituída posteriormente pela Portaria $\mathrm{n}^{0} 1.820$, de agosto de 2009 , que dispõe sobre os direitos e deveres do exercício da cidadania dos usuários da saúde em todo o país:

É direito dos cidadãos atendimento acolhedor na rede de serviços de saúde de forma humanizada, livre de qualquer discriminação, restrição ou negação em função de idade, raça, cor, etnia, orientação sexual, identidade de gênero, características genéti-

11 Gays, Lésbicas, Transgêneros e Bissexuais, conforme texto do próprio programa. 
cas, condições econômicas ou sociais, estado de saúde, ser portador de patologia ou pessoa vivendo com deficiência, garantindo-lhes:

I) a identificação pelo nome e sobrenome, devendo existir em todo documento de identificação do usuário um campo para se registrar o nome pelo qual prefere ser chamado, independentemente do registro civil, não podendo ser tratado por número, nome da doença, códigos, de modo genérico, desrespeitoso ou preconceituoso. (MINISTÉRIO DA SAÚDE, 2009).

Embora as políticas públicas possuam propostas de igualdade de atendimento, garantida pela Constituição Brasileira, as relações sociais cotidianas vivenciadas pelas travestis evidenciam que na realidade o que estrutura estas relações é a desigualdade no atendimento, interditando este grupo específico ao acesso garantido por lei da Saúde Pública.

\section{'SE TE CHAMAREM, TE CHAMEM PELO NOME DE MULHER'}

A sociedade ocidental contemporânea tem como uma de suas características a linearidade entre sexo, gênero e desejo (BUTLER, 2003). Assim, os corpos que não têm correspondência com esta característica linear -contrariando aos padrões estabelecidos de normalidade - serão nomeados como desviantes, reproduzindo o efeito da normalidade e a manutenção de sua 'ordem natural'. Um dos grupos que justamente tensiona esta ordem linear é o das travestis.

Segundo Peres (2007), as definições da língua portuguesa para os termos 'travesti' e 'travestismo' não correspondem à definição da travesti brasileira, pois insinuam farsa ou imitação. Para o autor, as travestis são pessoas que, a partir de artefatos, acessórios, atitudes, transformação de seus corpos através de hormônios, aplicação de silicone industrial, intervenções cirúrgicas e estéticas, se aproximam da corporeidade feminina, o que lhes traz um bem-estar biopsicossocial.

Outra discussão refere-se à conexão entre a palavra travesti e transgender. Este último termo, lido no Brasil como 'transgênero', refere-se ao transitar entre os papéis de gênero e. neste sentido, transgredindo a ordem hegemônica (SILVA, 2009c). Como tratado por Browne (2004), isto se refere à existência de pessoas que vivem suas vidas a partir de descontinuidades entre o sexo e a vida sexuada, vivendo seu cotidiano entre categorias de masculino/feminino. Assim, neste grupo estão incluídos as drag queens, transvestites, drag kings, cross-dresser, transexuais, transgênero M-F (male-female, ou mulher-trans) ou F-M (female-male, ou homem-trans).

Para Silva (2009c), mesmo a palavra 'travesti' tendo o significado de apropriação de alguns elementos do gênero oposto, encaminhado tanto a partir de fetiches ou irreverência social, este significado não se refere à travesti brasileira. Corroborando com o afirmado pela autora, a partir do contato e convivência com travestis, para este grupo o termo travesti refere-se a uma busca constante e integral da feminilidade, a partir do par vestimenta/maquiagem/adereços e comportamentos sociais. Mas, além disso, uma 
busca constante da transformação do corpo, a partir da utilização de hormônios e silicone, sem que isso se finalize em uma operação de trangenitalização. Desta forma, a palavra 'travesti' tem pouca correspondência com a palavra 'transvestite'.

Outra característica evidenciada a partir da convivência com o grupo de travestis é da relação entre a palavra 'travesti', doença e a prostituição. Na presente discussão não desconsideramos que estas relações também não existam em relação aos termos acima elencados. O que salientamos é a especificidade de características das travestis, grupo focal da presente discussão, em relação aos termos transgender e transvestite.

Por outro lado, o próprio movimento político travesti brasileiro pensa o termo enquanto produto nacional, indicando que tanto a sociedade brasileira como a produção teórica anglófona não se apropriaram destas terminologias:

A identidade travesti é plenamente assumida nos movimentos políticos, cuja participação travesti é acentuada. A sigla 'GLBT', que deriva da Conferência Nacional de Gays, Lésbicas, Bissexuais e Transgêneros, foi questionada pelos integrantes do movimento e provocou a sua modificação para 'GLBTT', que expressa Gays, Lésbicas, Bissexuais, Travestis e Transexuais. A inclusão de um segundo ' $T$ ' marca a necessidade de explicitação da diferenciação entre travestis e transexuais. Outras duas siglas importantes a serem consideradas são a do Encontro Nacional de Travestis, Transexuais e Transgêneros que Atuam na Luta Contra a AIDS ${ }^{12}$ - ENTLAIDS e a da Articulação Nacional de Travestis, Transexuais e Transgêneros ${ }^{13}$ - ANTRA. (SILVA, 2009c, p. 5).

Uma discussão necessária refere-se à abordagem de Kulick (2008) em relação à travesti, a partir da prostituição, do sexo, gênero e cultura no Brasil. Segundo o autor, na afirmação da subjetividade travesti, enquanto uma identidade brasileira, segundo suas reflexões etnometodológicas, o sexo e o gênero não são estados ontológicos, mas resultado de todas as práticas cotidianas. Assim, para o autor, a travesti enquanto uma forma de transgenderismo, não seria uma ocorrência natural ou arbitrária, mas emerge de especificidades espaciais e temporais.

O equivoco de Kulick (2008) assenta-se na limitação da prática sexual travesti apenas relacionada à passividade sexual. Como visto em suas palavras, "o lócus da diferença de gênero é o ato da penetração. Se a pessoa 'só' penetra, é homem. Se a pessoa é penetrada, é diferente de homem - e aí pode ser um 'viado' ou uma mulher" (KULICK, 2008, p. 236). Mesmo que a reflexão de Kulick seja importante, a partir da afirmação de que o grupo de travestis possuem especificidades próprias, falha quando simplifica generalizando todas as travestis brasileiras a este modelo binário 'penetrante - penetrada'.

Consideramos que a generalização da categoria transgender a várias possibilidades de questionamento da linearidade entre sexo, gênero, prática sexual e desejo relaciona-se a uma forma de 'estrabismo anglófono', como nomeado por Whitehand (2005). Segundo este autor, a pequena atenção direcionada pela produção anglófona à produção teórica

12 Movimento que marca a organização da comunidade travesti brasileira em 1993.

13 Informação disponível em: http:/ / www.antrabrasil.com. Acesso em: 24/09/2009. 
de outras línguas é uma condição que existe de forma acentuada desde o pós II Guerra Mundial, condição esta de carácter mais político que intelectual. A partir da discussão sobre a hegemonia de revistas geográficas e sua indexação, Whitehand aponta que estas se colocam como internacionais apenas no mundo anglófono internacional. Além da fraca representação de reflexões não anglófonas, para o autor a maioria dos pesquisadores anglófonos não dominam outras línguas. Assim, outras discussões são desconhecidas, fato que ocorre, paradoxalmente, ao lado da nossa tomada de consciência, pela produção não anglófona, da necessidade de diálogo internacional.

Conectada à proposta de Peres (2007), Louro (2004) argumenta que os sujeitos considerados 'comuns' e 'normais' também se utilizam de artefatos, acessórios e atitudes que, aos olhos da sociedade heteronormativa, são considerados 'adequados' e 'válidos', pois todos utilizamos de signos e símbolos para dizer o que somos. No entanto, Louro (2004) alinha-se à proposição de Butler (2003) e Valentine (1993), no sentido de que aqueles (as) que transgridem os limites de gênero e sexualidades são marcados como sujeitos desviantes, escapando da 'normalidade' imposta pela ordem societal dominante.

Nessa perspectiva de desvios à normalidade social, as espacialidades da saúde reproduzem um texto hegemônico que muitas vezes interdita o acesso das travestis às espacialidades, por não atenderem a essa ordem binária, como afirma Butler (2008). Segundo a autora, isto se refere aos 'corpos abjetos', ou seja, aqueles que são considerados fora da norma vigente, destituídos de humanidade, relegados à invisibilidade, ou corpos que não são importantes, pois, como se pode ler em suas palavras:

Esta matriz excludente mediante a qual se formam os sujeitos, requer pois a produção simultânea de uma esfera de seres abjetos, daqueles que não são 'sujeitos', mas que formam o exterior constitutivo do campo dos sujeitos. $\mathrm{O}$ abjeto designa aqui precisamente aquelas zonas 'invisíveis' e 'inabitáveis' da vida social que, contudo, estão densamente povoado por aqueles que não têm a hierarquia de sujeito, mas cuja condição de viver sob o signo do 'invisível' é necessária para circunscrever a área dos sujeitos [...]. Nesse sentido, pois, o sujeito se constitui através da força da exclusão e da abjeção, uma força que produz um exterior constitutivo do sujeito, um exterior abjeto que, depois de tudo, é 'interior' ao sujeito como seu próprio repúdio fundamental. (BUTLER, 2008, p. 19 - 20).

A abjeção desses corpos é oriunda de rótulos e estigmas (GOFFMAN, 2004). Os sujeitos acabam ocupando, a partir disto, espaços restritos e marginalizados, ou vivendo interdições espaciais. Embora sejam corpos 'marcados' e carregados de consequências espaciais, pela sua não correspondência à normalidade, as travestis visam buscar legitimar sua presença social, sendo tratadas e reconhecidas como compositoras da sociedade, tanto individualmente, como através da participação das Ong's LGBT que lutam e dão voz a essas pessoas.

Esses elementos de interdição foram retirados das entrevistas semi-estruturadas, realizadas com oito travestis que residem na cidade de Ponta Grossa, PR, e que em algum momento de suas vidas tiveram como atividade a prostituição. Assim, do total de 
evocações produzidas através do processo de pesquisa, as espacialidades evidenciadas ${ }^{14}$ pelas falas referem-se a: Ong's LGBT (2\%), Espacialidades Legais (3\%) e Ilegais (6\%) de transformação do corpo, Cidade (6\%), Casa (8\%), Território da Prostituição (22\%) e Espacialidade da Saúde (33\%). Todavia, devido ao escopo da presente discussão, mergulhamos nas espacialidades relacionadas com as espacialidades legais e ilegais da transformação do corpo e das espacialidades da saúde, relativas a hospitais, centros municipais e unidades de saúde.

A partir das evocações levantadas, após a transcrição total das entrevistas, em relação às Espacialidades da Saúde chegou-se ao resultado do gráfico a seguir:

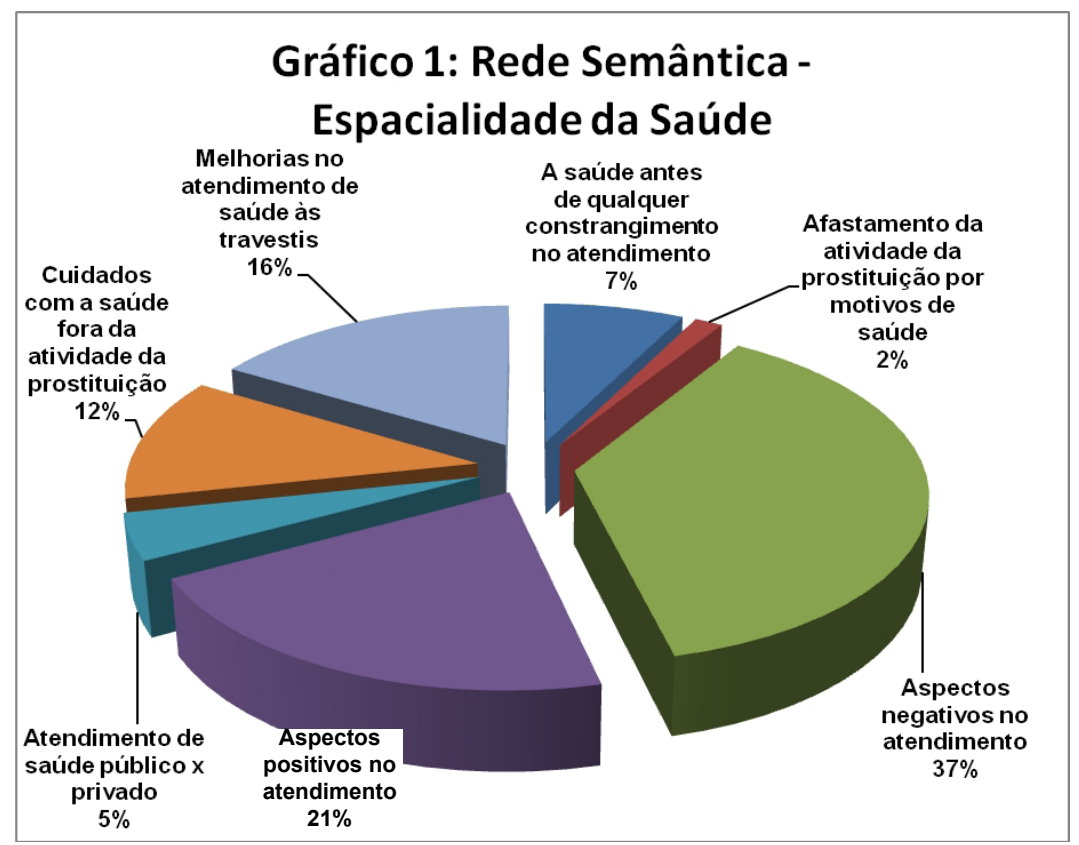

Fonte: Entrevistas realizadas entre os meses de maio e agosto de 2012. Organização: CARNEIRO, Marcia Tobias. 2012.

Quando as falas tratavam da Espacialidade da Saúde, a partir da categoria 'Aspectos negativos no atendimento', maior percentual registrado, diziam respeito aos constrangimentos vivenciados partindo dos profissionais de saúde, que, segundo as travestis, deveriam ser mais sensibilizados e orientados para o atendimento das mesmas. Estes constrangimentos referem-se também ao silêncio e aos olhares de outros que transmitem o preconceito contra a presença das travestis nas espacialidades da saúde, remetendo ao que Silva (2013) fala sobre a produção do espaço interditado.

$\mathrm{O}$ tratamento dado às travestis através destes espaços fazem referência à questão do atendimento pelo nome social de escolha da travesti, que segundo o Ministério da Saúde (2009) é direito de qualquer cidadão, independente do documento de identificação do usuário. A fala a seguir mostra como devem ser tratadas nas espacialidades da saúde:

14 Do total de evocações, 10\% estiveram relacionadas a Espacialidades não especificadas e 10\% a Espacialidades não evidentes. Nestas evocações, as falas realizavam considerações pessoais, sem a conexão com espacialidades, mesmo que consideremos que todas as experiências são vivenciadas nas mesmas. 
Pode ser assim como tá, normal e continuem chamando a gente pelo nome de mulher, eu acho isso, e que tratem a gente como mulher né, que se for internada, coloque no quarto feminino, tem tudo que é lugar, que seja né, se te chamarem, te chamem pelo nome de mulher, acho que é isso como feminina mesmo né, porque não adianta colocar você junto com os homem, né porque daí eles se constrangem, vão se constranger e você também né [...]. (Entrevista com a travesti ‘ $\mathrm{E}^{15}$ ', realizada no dia 30 de maio de 2012, em Ponta Grossa, PR, grifo nosso).

Em muitas situações vivenciadas esta determinação não é cumprida, gerando constrangimento a estas pessoas. Outro aspecto levantado nos relatos sobre as vivências nas Espacialidades da Saúde são as recordações de morte, considerando-se a presente negligência de atendimento para com as travestis. Estas experiências foram vivenciadas por aquelas que presenciaram os momentos de aflição e sofrimento daquelas travestis que não sobreviveram, por conta do descaso médico. Esses processos de interdição ao acesso à saúde podem ser vistas nos relatos seguintes:

[...] olhar de preconceito né, que acham que, são pessoas que nada a ver com a gente né não sabe da vida particular da gente, você olha assim e aquela pessoa às vezes é mais necessitada que você, sabe, e a pessoa tem a petulância de te olhar com preconceito, isso te dói mais, sabe como que é, por que primeiro a gente tem que olhar a gente, pra depois olhar os outros, é tipo assim, é igual a você pegar e olhar um aleijado na rua e fica olhando pra aquilo ali, gera um constrangimento só de você olhar, não é, então pra gente é a mesma coisa, só de olhar e vê uma travesti, mas isso também é mais curiosidade das pessoas, né, são pessoas leigas, ouvem falar da travesti, mas nunca viu travesti, aí quando vê o travesti, não é, aí se choca. (Entrevista realizada com a travesti ' $\mathrm{P}$ ', no dia 5 de julho de 2012, em Ponta Grossa, PR).

[...] É mudança de nome, quarto, daí você tem aparência de feminina, e te jogam no quarto de homem, eles vão te procurar fulano de tal, olham pra tua cara, chamam você pelo nome e não se tocam que você tá ali na frente deles. (Entrevista realizada com a travesti ' $\mathrm{M}^{\prime}$, no dia 30 de maio de 2012, em Ponta Grossa, PR)

Ah tem né, tem de uma que morreu, ela tava com doença né, quando ela foi ao médico, num particular, pago, pago, pois eles pegaram ela, colocaram numa sala vazia sozinha, e deixaram lá pra que ficasse morrendo, deixaram ela lá. Por ser travesti? Por ser travesti, aquilo lá foi preconceito total mesmo, e sendo pago né. [...] Foi em Ponta Grossa. [...] Faz uns 8 anos atrás, sendo pago, então acho que não tinha que ter isso por ser travesti, e se fosse outra pessoa que tivesse com a mesma doença né, acho que teria sido atendido melhor [...] muitas que tem não falam né, daí só vai saber quando aconteceu, ou quando tá acontecendo, porque elas não se abrem, não contam né, por causa de ser uma coisa intima delas, e elas não querem contar, porque uma começa falar pra outra e outra acaba sabendo, então [...] Nesse hospital foi o próprio pai dela que colocou, ela que pagou tudo, mas o atendimento era zero, atendimento

15 Procurando proteger nossas fontes, utilizamos apenas as iniciais dos nomes de cada travesti que cedeu sua história de vida para a construção da presente discussão. 
zero mesmo, não dá nem vontade de ir olhar, porque é muito triste você ser jogado no canto ali, porque é que nem eu falei, se for pra ficar desse jeito, prefiro morrer de uma vez né, que você se acabando aos poucos, menina ainda mais sendo pago, isso no pago já foi assim, imagine no público. (Entrevista realizada com a travesti ' $E$ ', no dia 30 de maio de 2012, em Ponta Grossa, PR).

É que nem eu falei pra você, enquanto eles não descobrem que a gente, enquanto você não dá o documento, tudo bem, se deu o documento... eu sempre falo pra todo mundo, eu acho que na área da saúde, os profissionais da saúde eles tinham que ter uma capacitação é, mais intensa em como atender as travestis, porque existe o Plano de Ações e Metas aprovado Nacional, que você tem que ser tratado com o teu nome social, você tem que ser registrado pelo seu nome, mas o teu nome social tem que tá sempre, você tem que ser chamada pelo nome social, e não pelo nome de batismo, o social que você usa, é um direito que nós temos, tanto é que tem muitas que fizeram, que já tão fazendo a documentação do nome feminino, sem ter cirurgia, já tão conseguindo, só que é muito burocrático, você tem que ter dinheiro pra gastar, o juiz que vai ler o teu processo vai ter que se sensibilizar pelo teu problema, que você tem o sonho de ter o nome social, de ser chamado só de ' $\mathrm{F}$ ', o juiz tem que se sensibilizar pelo processo que ele lê ali, se ele acha que deve ele assina e você na hora vai ter sua documentação. (Entrevista realizada com a travesti ' $F$ ', no dia 4 de junho de 2012, em Ponta Grossa, PR).

No tocante à Espacialidade Legal de transformação do corpo, as evocações referem-se à busca pela feminilidade por meio de intervenções cirúrgicas ditas legais, entendidas como possuindo menos riscos à saúde de quem a elas se submete. A este respeito, obtivemos os seguintes resultados:

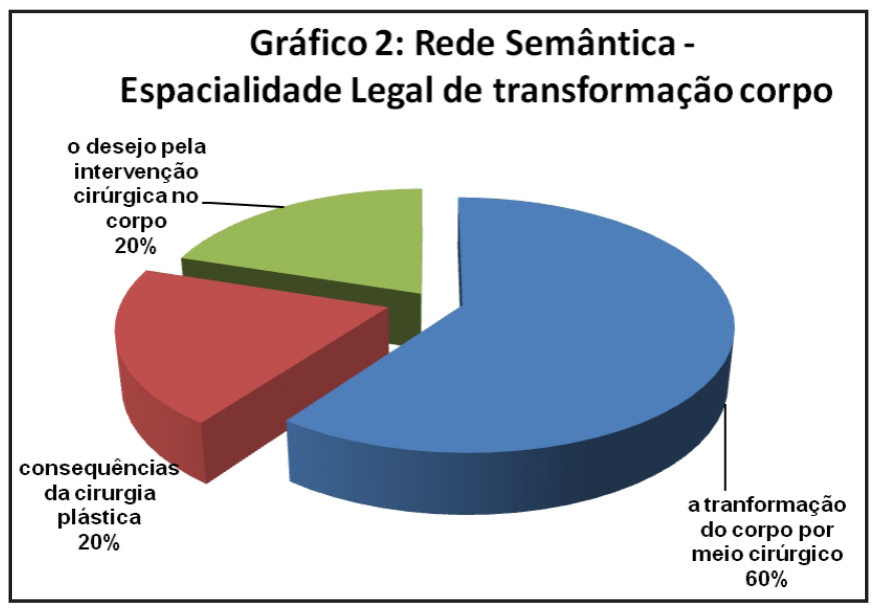

Fonte: Entrevistas realizadas entre os meses de maio a agosto de 2012 Organização: CARNEIRO, Marcia Tobias. 2012

Cabe salientar que a Espacialidade Legal de transformação do corpo resultou em apenas 3\% das falas, tratando-se de uma minoria que relatou sobre o assunto em específico. No que diz respeito à categoria de 'A transformação do corpo por meio cirúrgico', 
os relatos eram sobre a busca da corporeidade feminina através de um método mais seguro, que, por causa da atividade da prostituição se faz necessária para que não fiquem suscetíveis a maiores riscos para a saúde. A preocupação com a saúde é evidente na fala a seguir:

Não, foram todas legais, todas legais. [...] Prótese, fiz tudo direitinho... Ah eu penso em fazer mais uma cirurgia plástica, mas com cirurgião, não com esse meio (bombadeiras $\left.{ }^{16}\right)$. (Entrevista realizada com a travesti ' $\mathrm{P}^{\prime}$, no dia 5 de julho de 2012, em Ponta Grossa, PR).

Não distante do quantitativo encontrado pelos métodos legais de transformação do corpo, temos a procura pela facilidade e rapidez dos métodos ditos 'ilegais', e que em muitos casos, segundo as falas, se faz necessário. Nesta espacialidade ilegal de transformação do corpo retiramos das entrevistas as seguintes categorias:

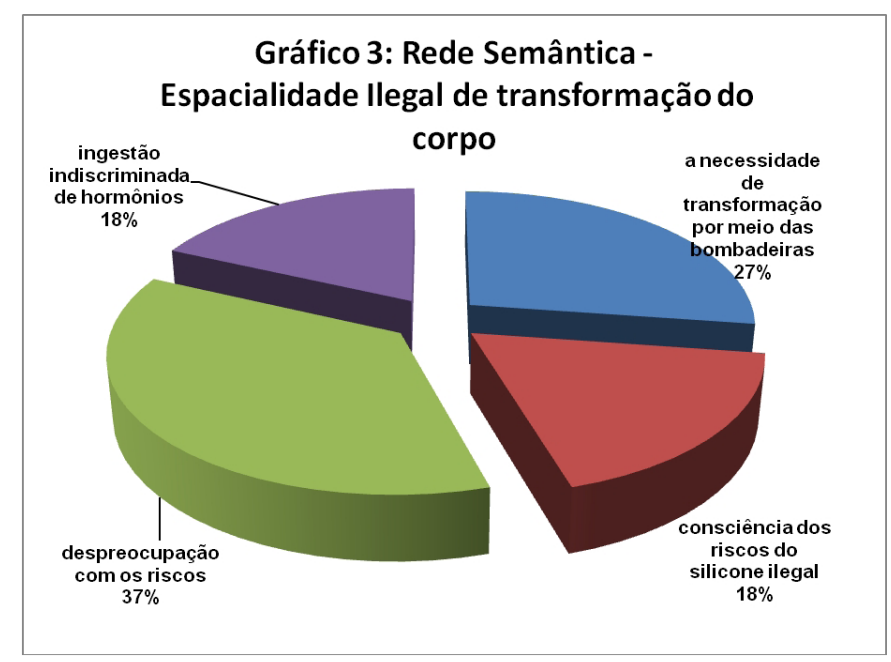

Fonte: Entrevistas realizadas entre os meses de maio a agosto de 2012 Organização: CARNEIRO, Marcia Tobias. 2012

Em relação à categoria com maior representatividade ‘Despreocupação com os ris$\cos ^{\prime}$, remetemos as falas que tratam da necessidade de transformação do corpo diante da atividade da prostituição, requisito que faz com que muitas optem, conforme relatado nas entrevistas, pelos métodos mais acessíveis, rápidos e de baixo custo, se comparados às cirurgias plásticas. A busca pelas bombadeiras é presente em grande parte das falas, porém o reconhecimento dos riscos não é considerado para a maioria, a partir do momento em que a profissional utilizar todos os procedimentos corretamente.

As intervenções no corpo pela ilegalidade faz com que a procura aumente à medida que os riscos não aconteçam. Portanto, a despreocupação é evidente, como visto nas falas sequentes:

Já faz 8 anos que eu tenho produto de bombadeira no corpo, e nunca me ocasionou nada, creio que não vai me ocasionar nada, na verdade você faz não sabendo das

16 Não consta na transcrição original. As 'bombadeiras' são pessoas, geralmente travestis, que aplicam silicone de origem industrial nos corpos de outras travestis, sem necessidade de intervenção cirúrgica. 
reações futuras. [...] Eu não acho normal, mas é a solução que você tem, você não tem condições financeiras né, depois que você tem condições financeiras você já se transformou. (Entrevista realizada com a travesti 'M', no dia 30 de maio de 2012, em Ponta Grossa, PR).

[...] tudo o que eu fiz de 'ilegal' foi colocar o silicone no seio, e um pouquinho no rosto... que era meio 'chupado' né, mas foi a única coisa. (O silicone industrial ${ }^{17}$ ) Industrial, no seio também bem pouco... meio copo em cada lado só, mas eu to querendo me arriscar de novo (risos). [...] Ah tem monas assim que a gente confia, confiava... porque a que a gente confiava já faleceu, que é a de Curitiba, esterilizava tudo, não usava a mesma seringa em outra pessoa, tudo era higiênico, mas essa agora que ficou no lugar dela, não me arrisco não... não me arrisco, porque como vocês souberam das duas travestis que foram parar no Pronto Socorro, foram bombadas por essa, que deu complicação, então nessa aí eu já não confio... por isso que eu falei que to pensando, não é que eu vou fazer, porque a que eu, a ' $\mathrm{D}_{2^{\prime}}{ }^{\prime}{ }^{18} \mathrm{e}$ a ' $\mathrm{J}$ ' confiava faleceu, e a gente fica meio assim né, vai pra fica bonitona, de repente tá de cama, é meio complicado [...]. A maioria busca pra ficar mais bonita, pra ter o corpo que elas desejam né, sorte daquela que já nasce com o corpinho feminino né, que não precisa de muita transformação, mas aquela que já tem o mais masculino, elas procuram ter o corpo feminino, porque elas procuram as bombadeiras ilegais né, graças a Deus eu não precisei muito não (risos). (Entrevista realizada com a travesti ' $\mathrm{D}_{1}^{\prime}$ ', no dia 11 de julho de 2012, em Ponta Grossa, PR).

A partir das evocações retiradas das entrevistas, podemos evidenciar que as Espacialidades da Saúde não são o resultado de um mercado invisível atuando sobre um espaço abstrato, mas são constituídas pelo que somos enquanto sociedade. Todavia, devemos levar em consideração que nas relações sociais não se opera alguma espécie de determinismo social, de que forma ele venha a existir.

As pessoas são sujeitos ativos, realizando escolhas constrangidas, mas de qualquer forma escolhas, estabelecidas segundo complexas relações de poder em variadas configurações, como proposto por Rose (1993). As relações de complexidade entre espacialidades da saúde legais e ilegais evidenciam que, mesmo que o atendimento da saúde seja uma prática que não leva em consideração a pluralidade humana, as travestis constituem estratégias de sobrevivência e de transformação do corpo.

As estratégias perpetradas cotidianamente pelas travestis nascem do fato de que, mesmo a partir da existência de propostas políticas de igualdade de atendimento para a pluralidade humana, as relações através da espacialidade da saúde mostram-se desiguais.

\section{CONCLUSÃO}

Evidenciamos nesta reflexão a relação entre espacialidades, atendimento de saúde e sexualidades, a partir da vivência travesti na cidade de Ponta Grossa, PR. Nos espaços

17 Pergunta da entrevistadora.

18 Devido ao fato de que duas travestis possuem seus nomes com inicial ‘ $\mathrm{D}^{\prime}$, diferenciamos suas falas a partir da utilização de 'D1" e 'D2". 
cotidianos, assim como nas espacialidades da Saúde, as ações de preconceito são ao mesmo tempo produzidas e reproduzidas segundo construções relacionais. Nesse sentido, as travestis, desafiando a ordem binária de organização social, colocam-se como pessoas que estão sujeitas à interdição e à exclusão do convívio social.

Mesmo que sejam/estejam invisibilizadas tanto pelo atendimento da saúde quanto pelas discussões relacionais entre atendimento e sexualidades, esta demanda coloca a problematização deste fenômeno enquanto um projeto político. Pensar a Ciência a partir desta perspectiva orienta a produção científico-geográfica segundo a produção de inteligibilidade da vivência de sujeitos silenciados.

E, talvez, subverter a ordem instituída que naturaliza injustiças sociais cotidianas, promovendo assim um atendimento de saúde que atenda a todas as especificidades de cada grupo social, efetivando as políticas públicas existentes e propondo-se a dar suporte para a construção de outras políticas, que garantam o acesso à saúde por equidade, sem preconceito.

\section{REFERÊNCIAS}

BARDIN, Laurence. Análise de conteúdo. Lisboa: Edições 70, 1977.

BRASIL. Ministério da Saúde. Departamento de DST, AIDS e Hepatites Virais. Disponível em: <http:/ / www.aids.gov.br/>. Acesso em: 12 maio 2012.

Plano Nacional de Enfrentamento de Epidemia de AIDS e das DST entre Gays, HSH e Travestis. Brasília: Ministério da Saúde, 2007.

Política Nacional de Saúde Integral de Lésbicas, Gays, Bissexuais, Travestis E Transexuais. Brasília: Ministério da Saúde, 2010.

Portaria $n^{0} 013$ de 15 de fevereiro de 2006. Disponível em: <http:/ / www.capes.gov.br/images/ stories/download/legislacao/Portaria_013_2006.pdf.> Acesso em: 19 abr. 2012.

Portaria $\mathbf{n}^{0} 1.820$ de 13 de agosto de 2009. Disponível em:< http://portal.saude.gov.br/portal/ arquivos/pdf/carta_do_direitos_dos_usuarios.pdf> Acesso em: 19 abr. 2012.

Lei $\mathrm{n}^{0}$ 8.080, de 19 de setembro de 1990. Disponível em <http://portal.saude.gov.br/portal/ arquivos/pdf/Lei_8080_1990.pdf> Acesso em: 12 maio 2012.

BROWNE, Kath. Genderism and the Bathroom Problem: (re)materialising sexed sites, (re)creating sexed bodies. Gender, Place and Culture, vol. 11, n 3, p. 331 - 346, September 2004.

BUTLER, Judith. Cuerpos que importan: sobre lós limites materiales y discursivos del 'sexo'. 2. ed. Buenos Aires: Paidós, 2008.

CORRÊA, Roberto Lobato Corrêa. Espaço: um conceito-chave da Geografia. In: CASTRO, Iná Elias de; GOMES, Paulo Cesar da Costa. CORREAA, Roberto Lobato Geografia: Conceitos e Temas. 12. ed. Rio de Janeiro: Bertrand Brasil, 1995, p. 15-47.

COSGROVE, Denis. A Geografia está em toda parte: Cultura e simbolismo nas Paisagens Humanas. In: CORRÊA, Roberto Lobato et al (Org.) Paisagem, Tempo e Cultura. Rio de Janeiro: EdUERJ, 1998, p. 92-123.

FEYERABEND, Paul. Contra o Método. Rio de Janeiro: Francisco Alves, 1975.

FOUCAULT, Michel. A ordem do discurso. 3. ed. São Paulo: Loyola, 1996.

História da Sexualidade I: a vontade de saber. vol. 1. Rio de Janeiro: Graal, 1985. 
GUIMARÃES, Raul Borges. Saúde Urbana: velho tema, novas questões. Revista Terra Livre, São Paulo, n.17, p.155 -170, 2001.

KULICK, Don. Travesti. Prostituição, sexo, gênero e cultura no Brasil. Rio de Janeiro: Editora Fiocruz, 2008.

LEFEBVRE, Henri. The production of space. Oxford: Blackwell Plubishing, 1991.

LOURO, Guacira Lopes. Um corpo estranho: ensaios sobre sexualidade e teoria queer. Belo Horizonte: Autêntica, 2004.

MASSEY, Doreen. Pelo Espaço: uma nova política da espacialidade. Rio de Janeiro: Bertrand Brasil, 2008.

MCDOWELL, Linda. Geographers and sexual difference: feminist contributions. In: JOHNSTON, Ron; WILLIAMS, Michael. A century of British Geography. New York: Oxford University Press, p. 603-623, 2003.

MORIN, Edgar. Ciência com Consciência. Rio de Janeiro: Bertrand Brasil, 1996.

OBERHAUSER, Ann; RUBINOFF, Donna; BRES, Karen; MAINS, Susan; POPE, Cindy. Geographic Perspective on Woman. In: GAILE, Gary; WILLMOTT, Cort. (Orgs). Geography in America at the Dawn of the 21st Century. Oxford: Oxford University Press, 2003, p. 736-758.

ORNAT, Marcio Jose. Território da prostituição e instituição do ser travesti em Ponta Grossa - Paraná. Dissertação (Mestrado em Gestão do Território - Programa de Pós-Graduação em Geografia), Universidade Estadual de Ponta Grossa. UEPG, Ponta Grossa, 2008.

. Espacialidades travestis e a instituição do território paradoxal. In: SILVA, Joseli Maria. Geografias Subversivas. Discursos sobre espaço, gênero e sexualidades. Ponta Grossa: TodaPalavra, 2009, p. 177-210.

Território descontínuo e multiterritorialidade na prostituição travesti através do Sul do Brasil. 279 f. Tese (Doutorado em Geografia), Universidade Federal do Rio de Janeiro. UFRJ, Rio de Janeiro, 2011.

PEREHOUSKEI, Nestor Alexandre; BENADUCE, Gilda Maria Cabral. Geografia da Saúde e as concepções de sobre o território. Revista Brasileira de Ciências da Saúde. São Caetano do Sul, USCS. vol. 23, n.68, p. 34-44, set/dez, 2007.

PERES, Wiliam Siqueira. Travestilidades: apontamentos para uma estilística da existência. Seminário Homofobia, Identidade e Cidadania GLBTT. Anais. NIGS - Núcleo de Identidades Gênero e Subjetividades. Florianópolis, p. 1-16, 2007.

ROSE, Gillian. Feminism \& Geography. The limits of Geographical Knowledge. Cambridge: Polity Press, p. 137 - 143 / 150-160, 1993.

. Performing Space. In: MASSEY, Doreen; ALLEN, John; SARRE, Philip. Human Geography Today. Cambridge: Polity Press, 1999, p. 247-259.

SANTOS, Milton. Por uma Geografia Nova. São Paulo: Hucitec, 1986.

SILVA, Joseli Marial. Ausências e Silêncios do Discurso Geográfico Brasileiro: uma crítica a Geografia Eurocêntrica. In: SILVA, Joseli Maria (Org.). Geografias Subversivas: discursos sobre espaço, gênero e sexualidade. Ponta Grossa: Editora Toda Palavra, p. 55-92, 2009a.

A cidade dos corpos transgressores da heteronormatividade. In: SILVA, Joseli Maria. Geografias

Subversivas. Discursos sobre espaço, gênero e sexualidades. Ponta Grossa: TodaPalavra, 2009b, p. 135150.

Geografia, Gênero e Sexualidades: A Experiência Travesti. In: III COLÓQUIO NACIONAL DO NÚCLEO DE ESTUDOS EM ESPAÇOS E REPRESENTAÇÕES - NEER, Anais. Porto Velho,1 a 6 de novembro 2009c, p. 1-36.

Espaço Interdito e a Experiência Urbana Travesti. In: SILVA, Joseli Maria; ORNAT, Marcio Jose: CHIMIN JUNIOR, Alides Baptista. Geografias Malditas. Corpos, sexualidades e espaços. Ponta Grossa: TodaPalavra, 2013, p. 143-182. 
SOUZA, Marcelo Lopes de. Algumas notas sobre a importância do espaço para o Desenvolvimento Social. Revista TERRITÓRIO. Ano II, n. 3, jul/dez. LAGET/UFRJ. Garamond, p. 13-35, 1997.

WHITEHAND, Jeremy. The problem of anglophone squint. Area, vol. 37, nº 2, p. 228-230, 2005.

VALENTINE, Gill. (Hetero)sexing space: lesbian perceptions and experiences of everyday spaces. In: Environment and Planning D: Society and Space. v.11, p. 395-413, 1993.

Recebido em 14-10-2013

Aceito para publicação em 20-03-2014 